\title{
CIDADE CERCADA: \\ Um modelo irreversível de expansão urbana?
}

\section{Marla Jéssica Marinho}

Universidade Estadual de Campinas

Orientador da investigação: Gisela Cunha Viana Leonelli (UNICAMP)

marla_marinho@hotmail.com

\section{RESUMO}

A investigação tem como objetivo fomentar a discussão sobre a expansão urbana atual das cidades brasileiras pautada na privatização de espaços, onde a principal forma de expansão do solo urbano é por meio dos loteamentos ou condomínios horizontais fechados. A partir do estudo da evolução da expansão urbana por empreendimentos fechados de Indaiatuba - SP é possível ilustrar o crescimento da cidade murada.

Palavras chaves: Loteamentos Fechados; Expansão Urbana; Espaço Público.

\section{ABSTRACT}

The present study has the objective of fomenting the discussion about the current urban expansion of the Brazilian cities based on the privatization of spaces, where the main way the urban land expansion and growth is through closed subdivisions or gated communities. Through the case study of the urban expansion by gated communities the municipality of Indaiatuba - SP is possible to illustrate the growth of walled city.

Keywords: Gated Communities; Urban Expansion; Public Spaces. 


\section{INTRODUÇÃO}

A produção do espaço urbano é resultado de uma união de processos históricos associados às maneiras de apropriação do território que, a partir da expansão territorial urbana tende a criar novos modos de organização espacial da sociedade. Mudanças nessas formas de organização da população aconteceram em diversas fases no processo de evolução das cidades, de tal forma que acarretam alterações no processo de urbanização. 0 crescimento acelerado da população urbana produz nas cidades uma enorme demanda por terra urbanizada, seja para sediar as atividades econômicas, ou atender às necessidades de moradia. (Rigatti, 2002, p.38).

As mudanças no processo de urbanização no Brasil trazem consigo um novo modelo de segregação social e urbana que altera as relações entre espaços públicos e privados, com o surgimento de espaços de acesso público, porém de propriedade privada, como os shoppings centers. (Reis, 2006, p.12).

A pluralização da paisagem urbana brasileira revela novas práticas socioespaciais, novas formas de diferenciação e segregação urbana e assinala uma fragmentação territorial e social da cidade. Nesse sentido, um fenômeno urbano que contribui diretamente nesta diferenciação consiste na expansão urbana por condomínios horizontais e loteamentos fechados, presente com maior proeminência nas últimas décadas.

Rolnik (1988, p. 40) aponta que neste processo, há destruição do tecido físico e social formando a cidade como um "imenso quebra-cabeça", feito de peças diferenciadas, em que cada uma delas conhece somente o seu lugar e sente-se alheio aos demais. Ao mesmo tempo em que essa produção do espaço busca oferecer a novidade, ao se expandir na forma de condomínios horizontais e loteamentos fechados, não busca necessariamente o novo, como aponta Sposito (2004), ela produz a homogeneidade.

Sposito e Góes (2013) afirmam que este processo é percebido de dois aspectos: o da auto-segregação e o da segregação: "no que se refere à autosegregação, é o grupo com melhores condições (...) que opta pelo isolamento em relação ao conjunto da cidade que, para eles, é o espaço dos outros e, portanto, não mais de todos" (Sposito E Góes, 2013, p.281).

As estratégias utilizadas pelos agendes dessa produção do espaço urbano, bem como os valores que orientam o consumo destes novos "produtos" imobiliários, têm raízes em nossa formação socioespacial e indicam o interesse de auto-segregação de uma parte dos moradores destas cidades. (Sposito, 2003, p. 1)

O condomínio horizontal e o loteamento fechado são as formas urbanas que mais têm movimentado o setor imobiliário atual, no qual se vende a sensação de eficiência da segurança privada ao mesmo tempo em que se desqualifica a segurança pública (Hernandez, 2011). Sposito (2004) defende que as estratégias imobiliárias se repetem, em diferentes cidades e se sucedem para que as novidades envelheçam e os novos produtos ganhem preços maiores no mercado. O discurso utilizado para vender a mercadoria terra, edificações, equipamentos $e$ meios de consumo coletivo, além das áreas verdes é o da segurança e da qualidade de vida intramuros. Nesse sentido, "a expansão deles relaciona-se com a forma e o conteúdo da produção e reprodução do espaço urbano no atual processo de financerização". (Rodrigues, 2013, p. 02)

De acordo com Caldeira (2000, p.259), as cidades fragmentadas por "enclaves fortificados", como a autora denomina esse tipo de empreendimentos, perdem os princípios de acessibilidade e livre circulação, estes que estão entre os valores mais importantes das cidades modernas. Yázigi (2000, p. 130) discute essa relação apontando o fato da cidadania ser considerada à convicção da "autopertinência" a um universo social que compartilha um conjunto de representações e relações sociais de tal forma que consiste no exercício da responsabilidade do que é comum a todos. Assim, o estabelecimento de condomínios horizontais e loteamentos fechados acabam privando também a sociedade, em geral, de usufruir de áreas públicas que são privatizadas com a construção dos muros, o que contribui para a diferenciação das classes.

A interação de interesses diversificados, motivados por tendências socioeconômicas, acaba refletindo-se diretamente nas formações e características dos espaços públicos (Oliveira e Mascaro, 2007). Assim, tem-se que os espaços públicos apresentam também uma função social, onde pessoas de diferentes classes sociais podem interagir em ambientes diversificados. 
Tais evoluções no processo de urbanização de uma cidade acabam influenciando diretamente nas formas como a população utiliza os seus espaços públicos. Bartolo (2013) destaca que a produção dos espaços públicos gera uma demarcação física nas cidades, estas delimitações definem usos e funções, além de também constituírem uma fronteira simbólica para a cidade.

Devido a essas mudanças na distribuição do espaço urbano, buscar entender a influência das mesmas na dinâmica de um município, de tal forma que esses fatos podem explicar e direcionar os costumes das populações urbanas em um futuro próximo. Coloca-se em questão a hipótese de que, se continuarmos na direção do fenômeno de privatização dos espaços da cidade, nos tornaremos cada vez mais segregados socioespacialmente.

Aonde chegaremos com expansão urbana cada vez mais acelerada e pautada nos princípios de enclausuramento e privatização das cidades? Qual a dimensão que este fenômeno esta tomando nas cidades atuais, e qual o real crescimento desta "massa" murada nos municípios?

\section{OBJETIVO E METODOLOGIA}

Nesse contexto, o presente estudo tem o objetivo de fomentar a discussão sobre a expansão urbana atual das cidades brasileiras pautada na privatização de espaços e na cidade murada, onde a principal maneira de expansão e crescimento do solo urbano é por meio dos loteamentos fechados ou condomínios horizontais fechados. Diante desse contexto, a pesquisa trata da nova forma de expansão urbana, que privatiza os espaços públicos à medida que constroem os muros e guaritas de acesso que impedem a livre circulação das pessoas e fragmentam o espaço urbano-social das cidades, tornando as cidades cada vez mais muradas e privatizadas.

Tendo como estudo de caso a expansão das últimas décadas do município de Indaiatuba - SP, o primeiro passo metodológico foi caracterizar a inserção urbana de Indaiatuba na Região Metropolitana de Campinas e seu processo de expansão urbana, visando elucidar a importância do estudo de caso escolhido e interpretar o processo de urbanização que ocorre no município através da abertura de novos loteamentos nas ultimas três décadas. O segundo passo metodológico ocorreu com levantamentos e espacialização de dados, a partir das seguintes atividades:

a) Levantamento das aprovações dos loteamentos de Indaiatuba, no período de 1980 - 2016 a partir das informações e documentos da Prefeitura Municipal de Indaiatuba,

b) Levantamento e sistematização das informações dos loteamentos: área total loteada, quantidade de lotes, metragem média dos lotes, destinação de áreas para sistema viário, área institucional, sistema de lazer, área verde,

c) Distinção dos loteamentos abertos, e dos loteamentos fechados, nos períodos de 1980 - 2016 .

d) Espacialização dos loteamentos aprovados a partir das seguintes classificações: Aprovados e implementados abertos, aprovados e implementados fechados, nos períodos de 1980-1990, 1991-2000, 20012010, 2011-2016.

\section{ESTUDO DE CASO}

A importância do município como estudo de caso pode ser comprovada quando aprofundamos o conhecimento sobre o próprio município. Indaiatuba localiza-se no interior do Estado de São Paulo. Situa-se na região sudeste do estado e compõe a região metropolitana de Campinas - RMC, a qual foi fortemente influenciada pelo crescimento da macrorregião, conforme apresentado na figura 1. A cidade apresenta grande território e fortes influências do seu município vizinho: Campinas; cidade de grande impacto na região. Indaiatuba se localiza em uma região em franca expansão do interior do Estado de São Paulo, sendo um ícone do processo de expansão da região devido ao seu pioneirismo industrial. 


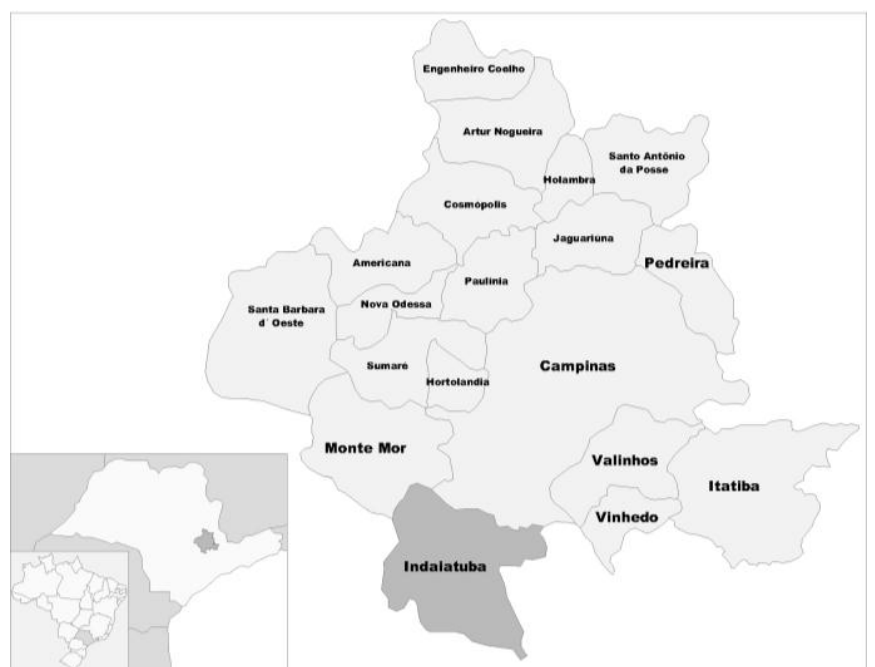

Figura 1 - Município de Indaiatuba na Região Metropolitana de Campinas (elaboração próprio autor)

O município de Indaiatuba, localizado na Região Metropolitana de Campinas (RMC), passa atualmente por uma intensa expansão urbana, como mostrado pela pesquisa realizada por Pera e Bueno (2015, p. 02), na qual discutem as fragilidades relacionadas à legislação urbanística que tangência a questão da expansão urbana da Região Metropolitana de Campinas, que, segundo as autoras, ocorre por um padrão de urbanização caracterizado como: disperso, fragmentado e com acentuada segregação socioespacial, tanto em escala municipal quanto metropolitana.

A população do município torna-se mais urbana com o decorrer do tempo, onde em 1970 era $73,18 \%$ urbana e em 2016 passa a ser 98,99\% urbana, o que caracteriza quase toda a população de Indaiatuba. Este processo se reflete no território do município, onde na divisão territorial da cidade a área urbana excede a área rural, como demonstrado na figura 2.
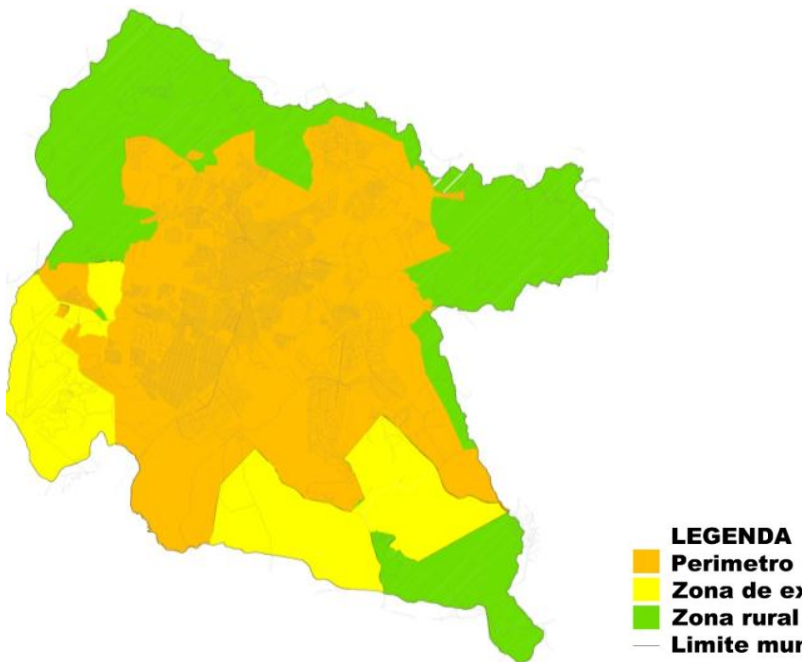

Perimetro urbano

Zona de expansão urbana

Zona rural

Limite municipal

Figura 2 - Divisão territorial do município de Indaiatuba. (elaboração próprio autor)

Dentre os municípios da Região Metropolitana de Campinas - RMC, alguns se destacam pela produção dessa expansão via empreendimentos fechados. Como aponta Freitas (2008), entre 2000 e 2007, 205 empreendimentos fechados foram aprovados na RMC. Dentre os municípios, neste período, Indaiatuba teve um número expressivo em relação aos outros municípios da região, com exceção de Campinas, conforme apresentado na tabela 1. 


\begin{tabular}{ll} 
Município & $\mathbf{N}^{\mathbf{0}}$ de empreendimento fechados \\
\hline Campinas & 50 \\
Itatiba & 18 \\
Jaguariúna & 10 \\
Paulínia & 17 \\
Indaiatuba & 32 \\
Valinhos & 25 \\
Americana & 15 \\
Monte Mor & 02 \\
Sumaré & 06 \\
Hortolândia & 03 \\
Vinhedo & 10 \\
Artur Nogueira & 04 \\
Holambra & 02 \\
Nova Odessa & 04 \\
Engenheiro Coelho & 02 \\
Pedreira & 02 \\
Santa Barbara d'Oeste & 01 \\
Cosmópolis & 02 \\
Santo Antônio de Posse & 00 \\
\hline
\end{tabular}

Tabela 1 - Loteamentos fechados e condomínios horizontais fechados aprovados na RMC entre 2000 e 2007 (Adaptado Freitas, 2008)

Comprova-se a importância do estudo de caso do município de Indaiatuba, por se tratar de uma cidade com grande expansão urbana, pautada na segregação socioespacial e murada, que trata do enfoque desta pesquisa, tornando possível identificar esse fenômeno e mostrar o crescimento das cidades muradas.

\section{RESULTADOS}

A produção dos loteamentos e condomínios horizontais fechados do município de Indaiatuba ocorre desde 1980, como identifica Caldeira (2000) para o caso brasileiro. Para entendimento do impacto dessa forma de urbanização, foi realizado o mapeamento dos loteamentos fechados da cidade de Indaiatuba. Identificou em uma primeira análise a distribuição desses enclaves, conforme apresentado na figura 2.

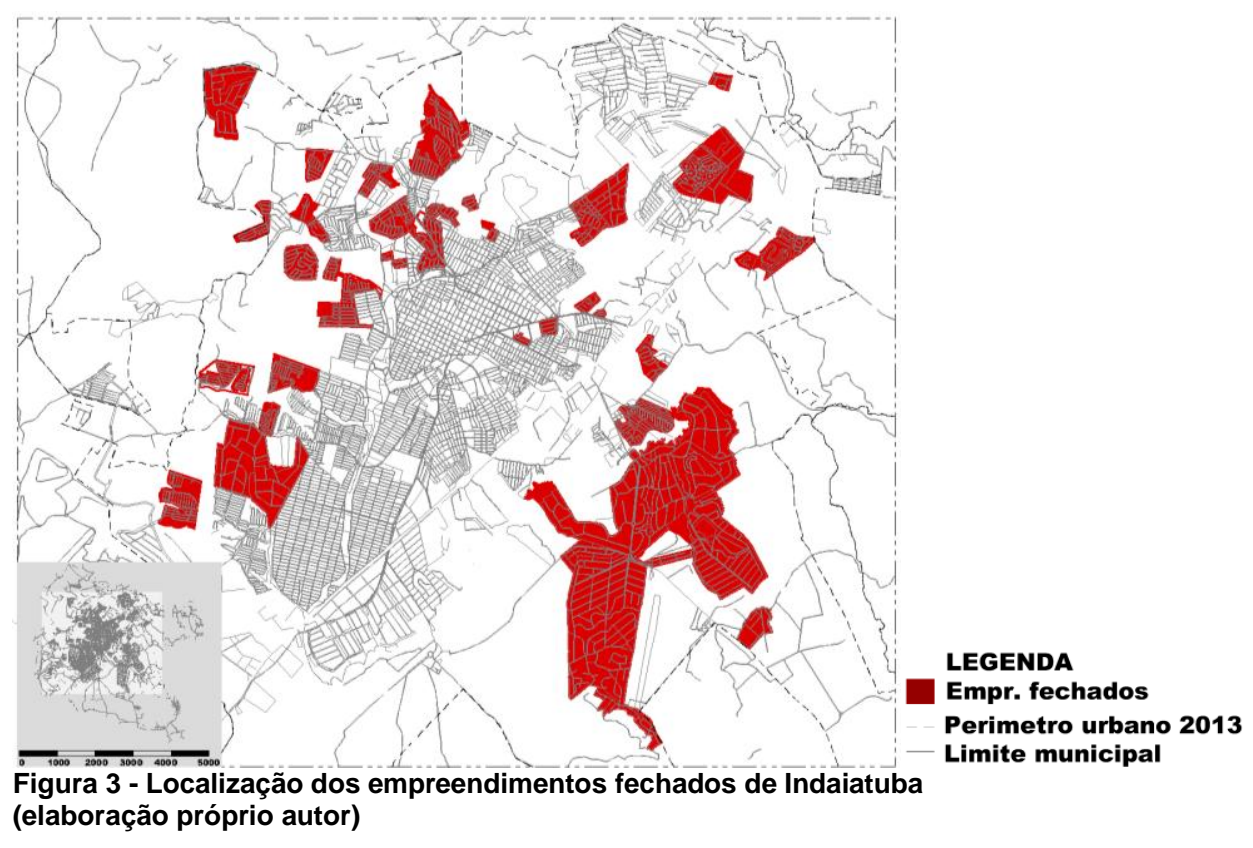


Em uma analise inicial, pode-se identificar um "cinturão" desses empreendimentos ao noroeste do município, e também uma grande área ao sul, onde em alguns momentos estes empreendimentos se chocam e uninem-se, formando uma grande mancha urbana "fechada", dificultando a mobilidade espacial da cidade nessas regiões.

No Brasil, o parcelamento do solo é a modalidade mais comum de expansão de áreas urbanas, por meio da incorporação de novas áreas às urbanizadas, na forma de loteamentos e desmembramentos, regulamentado pela Lei Federal 6.766 de 1976. Além da lei federal, ainda temos as leis estaduais e municipais, onde cada município rege o parcelamento do solo municipal, seguindo as regras e restrições da legislação federal.

A legislação municipal atual que rege o parcelamento do solo de Indaiatuba é a Lei no 3.525 de 18 de março de 1998, que "Dispõe sobre loteamentos, arruamentos, retalhamentos de imóveis em geral, e dá outras providências". Sobre as áreas públicas a lei descreve:

Capítulo III

Das áreas de uso público

Art. 32 - A área reservada a espaços de uso público deverá ser de no mínimo, 35\% (trinta e cinco por cento) da área a ser loteada.

$\S 11^{\circ}$ - A área destinada a sistema de lazer será de $10 \%$ (dez por cento) e a área destinada a fins institucionais de $5 \%$ (cinco por cento), em qualquer loteamento ou desmembramento submetido à aprovação da Prefeitura Municipal, ressalvado o disposto nos parágrafos seguintes.

[...]

Parágrafo Único - A área destinada a sistema de lazer será de 10\% (dez por cento) e a área destinada a fins institucionais de $5 \%$ (cinco por cento), em qualquer loteamento ou desmembramento submetido à aprovação da Prefeitura Municipal.

(Indaiatuba, 1998, p.16)

Destina-se, portanto, 35\% da área loteada para as áreas públicas. Porém, o Capitulo X da legislação municipal trata da concessão de uso, onde coloca:

Art. 63 - Fica o Poder Executivo autorizado a conceder independentemente de concorrência, a concessão administrativa de uso das áreas públicas (praças, áreas de lazer público ou áreas verdes, áreas institucionais e vias públicas) sem que suas destinações originárias sejam alteradas, pelo prazo máximo de 20 (vinte) anos, renovável por igual período, às sociedades civis sem fins lucrativos, que representem a maioria dos moradores e proprietários desses loteamentos, desde que:

I - o fechamento do acesso público às vias de circulação desses loteamentos não prejudique a utilização normal do sistema viário municipal existente;

II - As áreas institucionais sejam lindeiras a outras áreas públicas existentes à época da aprovação do loteamento;

III - as sociedades executem, por sua própria conta e risco, os serviços de conservação das áreas objeto da concessão de uso, bem como de seus equipamentos públicos, e ainda implantem e executem nos sistemas de lazer, a construção de equipamentos de lazer e esportes (quadras poliesportivas, piscinas, brinquedos infantis, etc.), às suas expensas, cujos projetos devem ser aprovados pela Municipalidade, e a construção iniciada e concluída em 02 (dois) anos após a concessão.

Parágrafo Único - A manutenção dos serviços de iluminação pública, nesses loteamentos, ficará sempre sob o encargo e responsabilidade do Poder Público Municipal.

(Indaiatuba, 1998, p.23)

A concessão de uso de bem público é considerada ilegal, pois, como cita Hernandez (2011, p.16), a transferência da posse de bem público inalienável e com destinação específica atribuída pela Lei Federal $\mathrm{n}$. . $^{\circ}$ $6.766 / 79$, no seu art. 22, jamais pode ser feita por meio de concessão de uso, o que caracteriza uma burla e flexibilização da legislação municipal para aprovar esse tipo de empreendimento.

O município de Indaiatuba, portanto, aprova loteamentos fechados. O fechamento dos loteamentos - e por consequência dos espaços públicos contidos nele - limita o direito de circulação e uso das áreas públicas fechadas intramuros. 
De acordo com o levantamento feito com base nos documentos de aprovação de loteamentos da prefeitura do município de Indaiatuba, no total temos 43 empreendimentos fechados aprovados e implantados no município, dos quais temos informações dos anos de aprovação de 35 deles.

Sintetizando essas informações identifica-se o crescimento dos loteamentos fechados na cidade de Indaiatuba. A sistematização das informações obtidas leva-nos a perceber o quão crescente é o fenômeno da cidade murada, onde o numero de empreendimentos fechados, ou seja, de loteamentos fechados aprovados, cresce a cada década analisada, onde o surgimento ocorre na década de 80, e ganha sua maior força entre 2001 e 2010.

\begin{tabular}{|c|c|c|c|}
\hline & $\begin{array}{l}N^{0} \text { de empreendimentos } \\
\text { fechados aprovados } \\
\text { (unidade) }\end{array}$ & $\begin{array}{l}N^{0} \text { total de lotes } \\
\text { (unidade) }\end{array}$ & $\begin{array}{l}\text { Area total murada } \\
\left(\mathrm{m}^{2}\right)\end{array}$ \\
\hline $\begin{array}{l}\text { Ano de aprovação não } \\
\text { identificado }\end{array}$ & 8 & 1945 & $1.835 .654,81$ \\
\hline 1980 à 1990 & 2 & 281 & $2.030 .958,63$ \\
\hline 1991 à 2000 & 6 & 1213 & $703.267,53$ \\
\hline 2001 à 2010 & 19 & 3803 & $3.792 .802,99$ \\
\hline 2011 à 2016 & 8 & 4630 & $2.298 .036,59$ \\
\hline Total & 43 & 11872 & $10.660 .720,55$ \\
\hline
\end{tabular}

No período de 1980 a 1990, temos apenas dois empreendimentos aprovados em 10 anos, já entre 1991 e 2000 o numero aumenta para 6 loteamentos aprovados nesta década. Entre 2001 e 2010 podemos perceber melhor o fenômeno, onde em uma década foram aprovados 19 loteamentos fechados, quase dois loteamentos por ano. Os anos de 2011 a 2016 continuam esta estatística, onde em apenas cinco anos já foram aprovados 8 loteamentos fechados.

A soma do número de lotes residenciais desses empreendimentos totalizam 11.872 lotes. Segundo o SEADE Fundação Sistema Estadual de Analise de Dados, em Indaiatuba a densidade é de 3,29 habitantes por domicílio (dados de 2010). Cruzando essas informações tem-se que aproximadamente 39.058 habitantes moram nos enclaves fortificados do município, o que significa 17\% (dezessete por cento) da população municipal.

A análise dos gráficos, apresentados na figura 4, mostra o crescimento dos empreendimentos fechados nos períodos analisados. Quando se trata do número de empreendimentos aprovados vê-se a crescente de unidades, ou seja, de bairros fechados aprovados no município nos períodos apresentados. Vale ressaltar que o ultimo período analisado, tem uma queda, pois se trata de um intervalo menor de tempo.

Quanto à análise gráfica da metragem quadrada murada em Indaiatuba, podemos observar que os dois empreendimentos dos anos de 1980 a 1990 apresentam área maior do que os seis empreendimentos do período de 1991 a 2000, o que volta a crescer nos anos de 2001 a 2010.

Porém a análise dos números de lotes mostra um crescimento uniforme em função do tempo, uma vez que no período analisado não houve período com déficit de unidades de lotes aprovados com relação ao período anterior. Assim, mesmo no ultimo período analisado, que compreende 5 anos e oito empreendimentos 0 número de lotes é maior do que o período anterior de 10 anos e dezenove empreendimentos.

Contudo, pode-se dizer que com o aumento uniforme do número de lotes oferecidos ao mercado, mesmo que as unidades de empreendimentos venham a diminuir, a oferta desse tipo de urbanização aos habitantes do município continua crescente, apontando o crescimento desses empreendimentos no mercado imobiliário e a preferência da população para este tipo de moradia, ressalvando também as condições de acesso às mesmas, que muitas vezes são limitadas a uma parcela específica da população. 


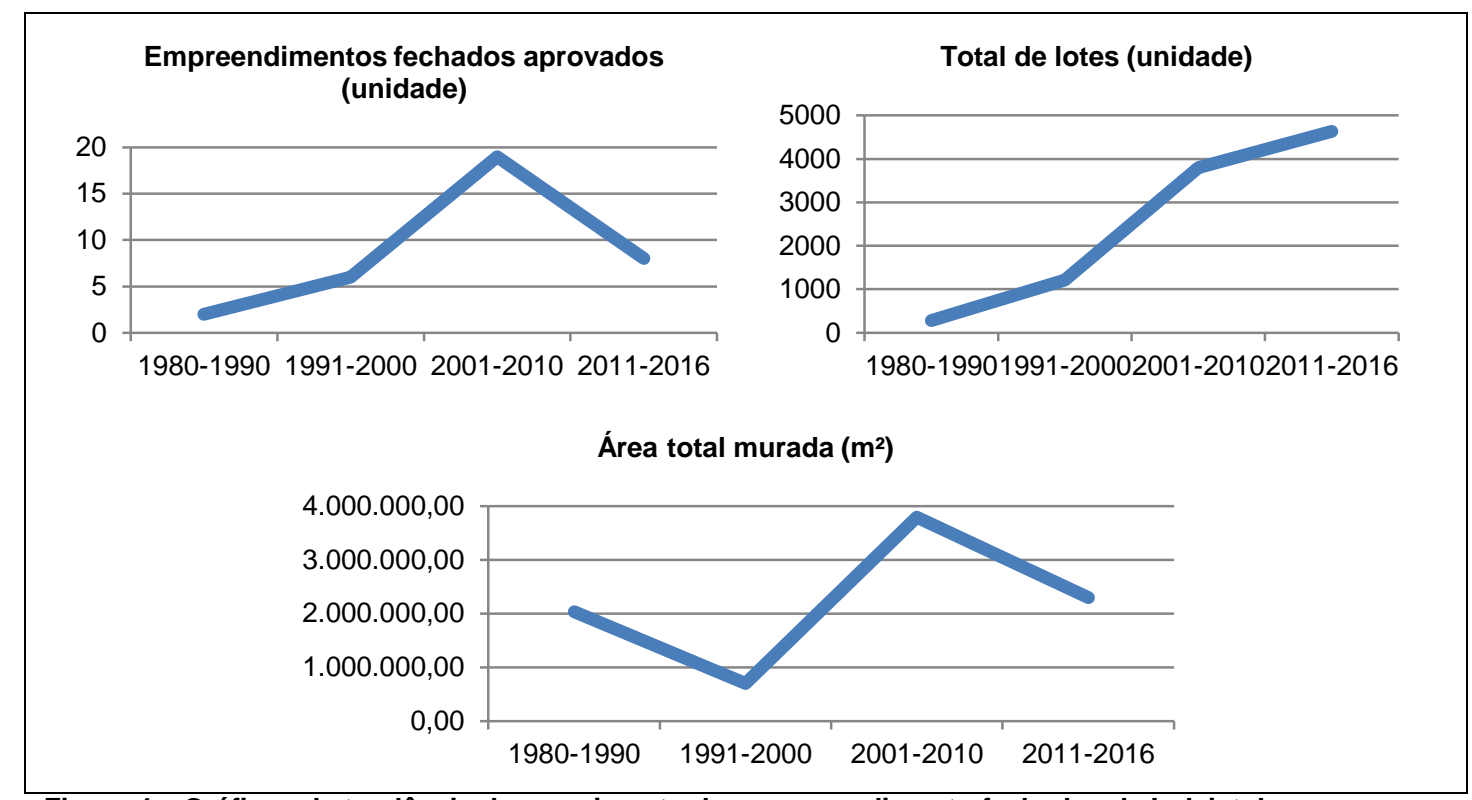

Figura 4 - Gráficos da tendência de crescimento dos empreendimento fechados de Indaiatuba (elaboração próprio autor)

A partir do mapa de localização dos empreendimentos fechados (figura 3) pode-se observar ainda que os mesmos ocupam as áreas mais periféricas da cidade, e que muitos se aglomeram formando grandes manchas fechadas na cidade, gerando impactos em relação à mobilidade. A segmentação da forma de produção do espaço urbano do município de Indaiatuba fica evidenciada pelo fracionamento do tecido urbano, descontinuidade territorial e destruição do tecido físico e social da cidade ocasionada pela presença desses enclaves residenciais, formando assim o "imenso quebra-cabeça" citado por Rolnik (1988, p. 40).

Vários impactos gerados pela crescente forma de urbanização segregada já foram confirmados pela literatura. Silva (2008) sintetiza alguns desses impactos apontados por diversos autores:

- Às experiências de segregação/exclusão (ROITMAN, 2005a e b; LOW, 2003 apud SILVA, 2008);

- Práticas de burla e flexibilização das leis (BEM-JOSEPH, 2004; DONALDSON, 2007; SILVA, 2007 apud SILVA, 2008);

- Aos limites da democracia e às novas forças e embates políticos e jurídicos (ANDRADE, 2001; WALKS, 2007; CALDEIRA, 2000 apud SILVA, 2008);

- Inconsistências quanto à questão da sustentabilidade urbana (LANDMAN, 2005 apud SILVA, 2008).

Destacam-se o avanço da urbanização sobre áreas rurais com a expansão dos perímetros urbanos, a privatização dos espaços públicos, os problemas de acessibilidade urbana, e os conflitos entre a gestão privada desses territórios e o poder público local.

Os impactos mais evidentes da produção da expansão urbana sob a prática de condomínios horizontais fechados e de loteamentos fechados é a privatização das áreas públicas e a quebra da continuidade do sistema viário, apontados por vários autores (LEONELLI, 2013; SPOSITO, 2013; CALDEIRA, 2000; FREITAS, 2008). Sobre a descontinuidade, Sposito (2006) aponta que ela não ocorre somente no sistema viário, mas que se trata de uma descontinuidade territorial.

[...] observando as relações entre o todo e as partes - a cidade e os loteamentos fechados - o que se nota é que as descontinuidades são, ao mesmo tempo, territoriais e espaciais. Os muros, de um lado, geram descontinuidades territoriais para os que estão de fora deles. A existência deles promove declínio do grau médio de mobilidade para quem está fora dos loteamentos, porque eles têm que contorná-los para ir de um ponto ao outro da cidade (SPOSITO, 2006, p. 194). 
Esta descontinuidade territorial pode ser percebida em Indaiatuba nos levantamentos espaciais dos empreendimentos fechados. Com base nos documentos de aprovação dos loteamentos da prefeitura municipal de Indaiatuba, e via Google Maps foi possível distribuí-los geograficamente e analisá-los. Baseando-se nos anos de aprovação dos loteamentos, foi possível identificar quantos loteamentos abertos e quantos loteamentos fechados foram aprovados por década analisada, e posteriormente espacializá-los no município.

Baseado nesta documentação resultou-se no mapeamento dos loteamentos diferenciando-se, portanto, quais e quantos loteamentos são abertos e quais e quantos são fechados. Elaborou-se o mapa dos loteamentos "aberto vesus murado". Desta forma, foi possível identificar o aumento da expansão do tecido urbano por loteamentos fechados do município, de acordo com o recorte temporal adotado.

A importância dessa comparação entre loteamentos abertos e fechados dentro do recorte temporal, ou seja, de cada década analisada, torna-se importante para identificar se os loteamentos fechados superam os loteamentos abertos no município nos últimos anos.

Cabe ressaltar que foram levantados 115 loteamento abertos (comerciais, residenciais e industriais) onde 81 apresentam ano de aprovação; e 43 loteamentos fechados residenciais, onde 35 apresentam data de aprovação.

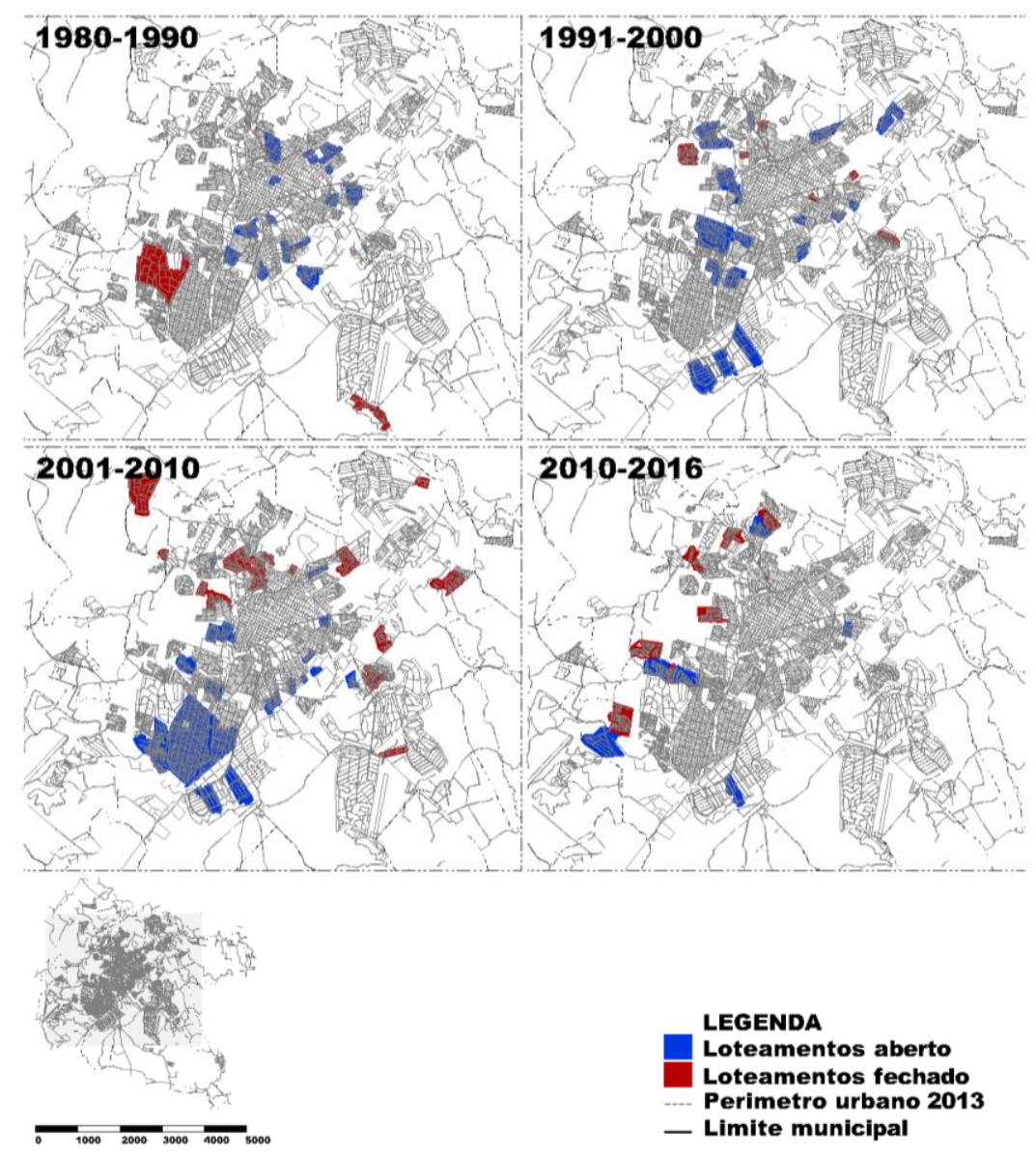

Figure 5 - Loteamentos do município: aberto X murados/fechados (elaboração próprio autor)

Constatou-se que Indaiatuba tem se expandido sob a lógica da privatização do espaço, conforme demonstrado na fig. 5. Pode-se notar que desde 1980 a expansão fechada está presente no município. No entanto, é entre 2001 e 2010 que se apresenta um crescimento significativo dos empreendimentos fechados. Entre os anos de 1980 e 2016 foram aprovados 43 empreendimentos, conforme mostrado na tabela 2, desses 19 no período de 
2001 a 2010. A proliferação dos empreendimentos fechados se mantém nos anos de 2011 a 2016, onde em cinco anos já foram aprovados 8 empreendimentos.

Porém notamos sempre a presença significativa dos loteamentos abertos em todos os períodos analisados, e dentro das informações obtidas. Identifica-se, que no período de 2010 a 2016 a mancha de loteamentos fechados, em vermelho na figura 6 , iguala-se a mancha de loteamentos abertos, apontando uma tendência equivalente de expansão urbana aberta e murada.

Aprofundando-se ainda mais na quantificação dessas áreas muradas em relação ao município, os estudos demonstraram que o solo parcelado no município de Indaiatuba nas últimas décadas apresenta uma parcela expressiva privatizada. Este processo se acentuou significativamente a partir da aprovação da lei municipal de parcelamento do solo em 1998 que permitiu o fechamento destes empreendimentos. A partir de então, a presença de urbanizações fechadas que eram exceções entre 1980 e 1998, tornou-se modelo consolidado de expansão da cidade a partir de 2000.

\begin{tabular}{|c|c|c|c|}
\hline & $\begin{array}{l}\mathrm{N}^{0} \text { de empreendimentos } \\
\text { fechados aprovados } \\
\text { (unidade) }\end{array}$ & $\begin{array}{l}N^{0} \text { total de lotes } \\
\text { (unidade) }\end{array}$ & $\begin{array}{l}\text { Area total murada } \\
\left(\mathrm{m}^{2}\right)\end{array}$ \\
\hline 1980 à 1998 & & 281 & $2.030 .958,63$ \\
\hline 1999 à 2016 & 3 & 9646 & $6.794 .107,11$ \\
\hline
\end{tabular}

Figura 6 - Dados dos loteamentos fechados aprovados em Indaiatuba antes (1980 a 1998) e depois (1999 a 2016) da aprovação da legislação municipal de parcelamento do solo,

Fonte: Autor

Comprova-se o uso da legislação municipal, em detrimento às normas federais de parcelamento do solo, onde o uso da legislação municipal é feito para favorecer uma urbanização e um crescimento pautado na segregação socioespacial. Pode-se dizer que o uso das legislações se torna conveniente ao anseio das partes interessadas, aplicada muitas vezes de forma desvirtuada. Seguir ou não a lei federal de parcelamento do solo para o controle da expansão urbana ultrapassa a questão da legalidade. A questão primordial é seu impacto urbanístico (LEONELLI, 2013).

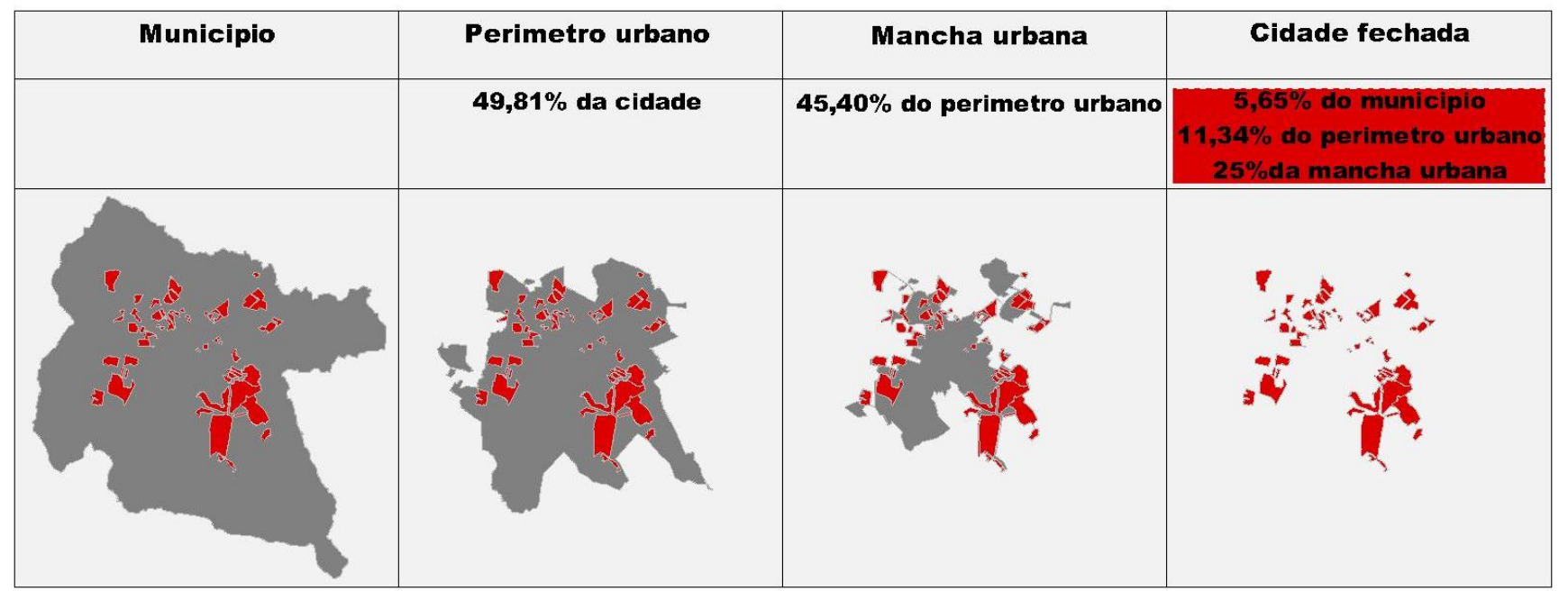

Figura 7 - Estratificação das áreas do município de Indaiatuba, com destaque para o percentual de área fechada do município. (elaboração próprio autor)

Com a especialização dessas áreas muradas do município de Indaiatuba foi possível apontar qual a porcentagem de área fechada do município, ou seja, quanto da cidade encontra-se intramuros. Assim, mostrase o impacto que esta urbanização traz à cidade e aos seus habitantes. O resultado foi bastante expressivo, como mostra a figura 7 , na qual $11,34 \%$ da área do perímetro urbano do município encontram-se murada, ou seja, dentro dos enclaves fortificados.

Este número é ainda mais expressivo se comparado com a mancha urbana do município, pois um quarto da mancha, ou seja, $25 \%$ da área urbanizada e consolidada da cidade de Indaiatuba encontram-se dentro dos 
muros. Mais uma vez, comprova-se esse padrão de urbanização segregada, e também segregadora, na medida em que o mercado impõe à população esse tipo de urbanização no seu modo de fazer e, principalmente, de vender a cidade.

Na medida em que vemos uma cidade que apresenta um perímetro urbano de $50 \%$ da área total do município, (sem calcular as áreas tituladas de expansão urbana), onde desse perímetro urbano $45 \%$ é a mancha urbana, ou seja, a cidade consolidada, o que realça a quantidade de áreas vazias dentro do perímetro urbano do município, que chegam a 55\% do perímetro urbano; e ainda, $1 / 4$ da mancha urbana esta em porções fechadas e restritas à parcela da população, dentro dos loteamentos fechados da cidade.

Esta análise leva a vários problemas em relação ao espaço urbano que está sendo consolidado no município apresentado, que pode-se dizer que é um modelo seguido pelos municípios da região em que ele se insere (Região Metropolitana de Campinas): um modelo fragmentado e com exacerbada segregação socioespacial.

\section{CONSIDERAÇÕES PRELIMINARES}

A expansão urbana das cidades brasileiras, bem como o que foi apontado em relação à expansão de Indaiatuba, tem se pautado em espaços fechados e privatizados, refém de um produto mercadológico em que a terra foi transformada. Influenciado por vários fatores, como segurança, lazer, convivência entre os comuns, bem-estar; este produto ganha força e acaba se tornando a forma mais comum de expansão urbana: a expansão urbana murada.

A partir da pesquisa em campo, é mostrada a cidade produzida por esta forma de urbanização, com foco no seu efeito cumulativo e não parcial. Como comprovado no estudo de caso, atualmente Indaiatuba conta com $25 \%$ da sua mancha urbana privatizada e fechada intramuros, onde residem $17 \%$ da população urbana. Isso mostra uma grande área do município consolidado fechado intramuros, onde somente uma pequena parcela da população detém seu uso, características de uma urbanização segregada sócio e espacialmente.

Mesmo que ainda ocorra a urbanização por loteamentos abertos na cidade, a produção dos empreendimentos fechados tem sido predominante na última década no caso do município estudado, mostrando que esse é o padrão mais recorrente de urbanização atual, de Indaiatuba.

Este trabalho permitiu concluir que a expansão urbana por loteamentos fechados tem produzido um cinturão periférico murado, privatizado, com baixa qualidade urbanística e privatização das áreas públicas que se encontram dentro desses muros. Especificamente no caso de Indaiatuba, mais do que a ação do mercado imobiliário, destaca-se a ação do planejamento urbano e das legislações urbanísticas como promotoras desta nova morfologia de expansão periférica.

No caso ilustrado, vimos que a expansão urbana esta pautada no modelo privatizado e murado. Nesta discussão, coloca-se a questão de qual é a proporção do efeito cumulativo desse fenômeno nas cidades atuais?

\section{REFERÊNCIAS}

ALVES, Adriana Corrêa. Qualidade de vida e processos sócio-ambientais em Indaiatuba - SP. Estudo de caso do bairro Jardim Morada do Sol. Dissertação de Mestrado - Universidade Estadual Paulista. Instituto de Geociências e Ciências Exatas. Programa de Pós-graduação em Geografia. Área de Concentração em Organização do Espaço. Rio Claro, 2003. 130 p.

BORTOLO, Carlos Alexandre de. O espaço público do parque do povo - Presidente Prudente - SP: reflexões geográficas. Revista Geografia em Atos. Departamento de Geografia da FCT/UNESP, Presidente Prudente, $n$. 13, v.1, janeiro a junho de 2013, p. 50-65. 
CALDEIRA, Teresa Pires do Rio. Cidade de Muros: Crime, Segregação e Cidadania em São Paulo. 1. ed. São Paulo: Editora 34 e Edusp, 2000.

EMPLASA. Empresa Paulista de Planejamento Metropolitano. Região Metropolitana de Campinas. 2012. Disponível em: < http://www.emplasa.sp.gov.br/home/artigo/?UserKey=regiao-metropolitana-decampinas\&Type=Indicador $>$.

FREITAS, Eleusina Lavôr Holanda de. Loteamentos fechados. Tese - Faculdade de Arquitetura e Urbanismo da USP. São Paulo, 2008.

HERNANDEZ, Isa Raquel da Silva Ota. A privatização dos espaços públicos nos loteamentos fechados em Uberlância/MG. Dissertação - Instituto de Geografia da Universidade Federal de Uberlândia, Uberlândia - MG. 2011.

INDAIATUBA. Lei no 3.525/1998. Dispõe sobre loteamentos, arruamentos, retalhamentos de imóveis em geral, e dá outras providências. Prefeitura Municipal de Indaiatuba, 18 março 1998.

LEONELLI, Gisela Cunha Viana. Loteamentos e condomínios: lei para que, lei para que? Mas qual lei? Anais do encontro da associação nacional de planejamento urbano e regional. Recife, 2013.

OLIVEIRA, Lucimara Albieri de; MASCARÓ, Juan José. Análise da qualidade de vida urbana sob a ótica dos espaços públicos de lazer. Porto Alegre: Ambiente Construído, v. 7, n. 2, p. 59-69, 2007.

PERA, Caroline Krobath Luz; BUENO, Laura Machado de Mello. Expansão urbana: como está sendo feita e para quem? Uma análise dos instrumentos de política urbana a partir do estudo da região metropolitana de Campinas-SP. VIII Congresso Brasileiro de Direito Urbanístico. Fortaleza, 2015.

RIGATTI, Décio. Loteamentos, expansão e estrutura urbana. São Paulo: Paisagem e ambiente, n. 15 p. 35-69, 2002

REIS, Nestor Goulart. Notas sobre a urbanização dispersa e novas formas de tecido urbano. São Paulo: Via das Artes, 2006.

ROLNIK, Raquel. O que é a cidade. São Paulo: Editora Brasiliense, 1988.

RODRIGUES, Arlete Moysés. Loteamentos murados e condomínios fechados: Propriedade fundiária urbana e segregação socioespacial. In A cidade contemporânea - segregação espacial. Org. Pedro de Almeida Vasconcelos, Roberto Lobato e Silvana Maria Pintaudi. São Paulo: Contexto, 2013.

SILVA, Veridiana Lima da. Mudanças na forma de ocupação do espaço urbano em Valinhos - SP: A expansão dos condomínios fechados. Dissertação - Instituto de Geociências, UNICAMP, Campinas, 2008.

SPOSITO, Maria Encarnação Beltrão. Loteamentos fechados em cidades médias paulistas - Brasil. In: SPOSITO, Eliseu Savério; SPOSITO, Maria Encarnação Beltrão; SOBARZO, Oscar. (Orgs). Cidades médias: produção do espaço urbano e regional. São Paulo: Expressão Popular, 2006, pp 175 - 197.

SPOSITO, Maria Encarnação Beltrão. Novos conteúdos das periferias urbanas das cidades médias do Estado de São Paulo, Brasil. Investigaciones Geográficas, Boletin Del Instituto de Geografia - UNAM, 2004. pp. 114139.

SPOSITO, Maria Encarnação Beltrão. A cidade dentro da cidade. Uma edge city em São José do Rio Preto. In Scripta Nova Revista Eletrónica de Geografía Y Ciencias Sociales: Universidad de Barcelona, 2003. Disponível em: <http://www.ub.es/geocrit/sn/sn-146(045).htm>.

SPOSITO, Maria Encarnação Beltrão; GOES, Eda Maria. Espaços fechados e cidades: insegurança urbana e fragmentação socioespacial. 1 ed. - São Paulo: Editora Unesp, 2013. 
YÁZIGI, Eduardo. O mundo das calçadas: por uma política de espaços públicos. São Paulo: Humanitas, 2000. 